\title{
Patterns, prevalence, risk factors, and survival of newborns with congenital heart defects in a Saudi population: a three-year, cohort case-control study
}

Muhammad Ali Majeed-Saidan ${ }^{1 *}$ (D, Merna Atiyah ${ }^{2}$, Amer N. Ammari ${ }^{1}$, Amal M. AlHashem ${ }^{3}$, Maha S. Rakaf ${ }^{4}$, Mohamed M. Shoukri' ${ }^{5}$, Ester Garne ${ }^{6}$ and Ahmed M. Kurdi ${ }^{4}$

\begin{abstract}
Background: Congenital heart defects (CHD) are the most common types of birth defects. The prevalence of CHD, mostly from retrospective studies, ranges between 2.1 and 10.7/1000 live births. For physicians to provide appropriate health care, it is important to know the prevalence of CHD within their patient populations. In this prospective study, we assessed the prevalence, risk factors, types, and survival of CHD among babies born to Saudi mothers over a three-year period.

Methods: In this prospective cohort study, all women delivered at Prince Sultan Military Medical City, Saudi Arabia over a three-year period and were recruited during their antenatal care visits or at delivery. Antenatal foetal anomaly scan, postnatal clinical examination, echocardiography, cardiac catheterization, and follow-up to 2 years of age were used to assess the patterns, prevalence, and survival of babies with CHD. A case-control study was nested within the original cohort to assess risk factors for CHD.

Results: Of 28,646 eligible births, 424 babies were diagnosed with CHD (14.8/1000 births), and 91 of these babies had severe CHD (3.2/1000 births). Associated non-cardiac anomalies were found in 40.1\% (170 of 424) of these babies. Trisomy 21 was the most frequent chromosomal anomaly. Within the first 2 years of life, 74 of 424 babies died (17.4\%). Among mothers with infants who had CHD without associated non-cardiac anomalies, risk factors for $\mathrm{CHD}$ included maternal age $\geq 31$ years, body mass index $\geq 30$, insulin-dependent diabetes, and an occupation of an unemployed housewife.

Conclusion: In the Saudi population we studied, the prevalence of CHD was higher than reported in other populations in the Middle East and in Europe. Plans to ameliorate modifiable risk factors and improve prenatal diagnosis of CHD are needed.
\end{abstract}

Keywords: Congenital heart defects, Birth defects, Prevalence, Risk factors, Survival

\footnotetext{
* Correspondence: msaidan@hotmail.com

${ }^{1}$ Division of neonatal medicine, department of Paediatrics, Prince Sultan

Military Medical City, W932, P. O. Box 7897, Riyadh 11159, Kingdom of Saudi

Arabia

Full list of author information is available at the end of the article
}

(C) The Author(s). 2019 Open Access This article is distributed under the terms of the Creative Commons Attribution 4.0 International License (http://creativecommons.org/licenses/by/4.0/), which permits unrestricted use, distribution, and reproduction in any medium, provided you give appropriate credit to the original author(s) and the source, provide a link to the Creative Commons license, and indicate if changes were made. The Creative Commons Public Domain Dedication waiver (http://creativecommons.org/publicdomain/zero/1.0/) applies to the data made available in this article, unless otherwise stated. 


\section{Background}

Congenital heart defects (CHD) are the most common types of major birth defects (BD) reported in the literature. CHD is the leading cause of birth defect-associated infant death and illness. This BD has a major effect on the quality of life for both the affected infants who survive with $C H D$ and their families [1]. The patterns and prevalence of CHD vary between studies [2, 3]. The prevalence of CHD reported in different studies ranges from 4/1000-50/1000 live births [2]. In a recent systematic review of $\mathrm{CHD}$ in Saudi Arabia, the incidence ranged between 2.1 and 10.7 per 1000 persons [3]. Van der Linde et al. reported on the birth prevalence of CHD diagnosed worldwide and found that the highest prevalence of CHD at 9.3/1000 live births was in Asian countries, and the lowest prevalence of CHD was 1.9/1000 live births in African nations [4]. Data on CHD prevalence and patterns in the Middle East, based on tertiary cardiac centres or from retrospective hospital-based analyses, vary widely [5-7]. One regional study from Saudi Arabia showed a very high prevalence of severe CHD (5.4/1000 live births) [7]. Prenatal diagnosis allows for improved perioperative outcomes for some severe CHD [8]. A high prenatal detection rate of $\mathrm{CHD}$ has been demonstrated in other countries but has not been examined in Saudi Arabia.

None of the studies from Saudi Arabia examined the known risk factors for CHD (insulin-dependent maternal diabetes mellitus, consanguinity, high maternal age, high parity, high maternal BMI, folic acid supplementation, sex, and medication exposure during the first trimester of pregnancy) or reported infant survival prospectively.

The aim of this study was to report the prevalence, patterns, risk factors, and survival of infants with CHD in an actual Saudi population of newborns over several years. This prospective cohort study included a nested case-control study to assess the contributions of the various risk factors to $\mathrm{CHD}$.

\section{Methods}

\section{Patients: cases and controls}

Inclusion criteria: The eligible cohort included all pregnant Saudi women who delivered at Prince Sultan Military Medical City (PSMMC) from 1 July 2010 through 30 June 2013. Only wives of Saudi army personnel were included in this study. Women who had an antenatal foetal anomaly scan (AFAS) between 18 and 22 weeks of gestation were enrolled in the study before the result of the anomaly scan was known. Consent for cord blood collection was obtained from the parents of babies with BD for future DNA studies.

A team of paediatric cardiologists assessed all foetuses and babies with suspected CHD based either on the AFAS findings or postnatal screening physical examinations.
Paediatric cardiologists performed 2D foetal echocardiography to assess foetuses with suspected CHD detected through a routine AFAS examination, and parents were advised of the findings. Newborn babies were reassessed again post-delivery. At postnatal examinations, babies with suspected CHD were referred to the paediatric cardiology team for further assessment and management. Echocardiography, cardiac catheterization, and cardiac surgery findings were utilized to confirm the type of CHD.

Special follow-up clinics led by paediatricians were created to reassess all other babies without a prenatal or neonatal diagnosis of a congenital anomaly. These babies were reassessed at 4-8 weeks of age through a clinical examination and pulse oximetry. A routine postnatal pulse oximetry test was introduced after the first year of the study for all other babies nursed in the postnatal wards. A cutoff value of $95 \% \mathrm{O}_{2}$ saturation was used to detect life-threatening CHD [9]. All babies with an $\mathrm{O}_{2}$ saturation of $<95 \%$ were referred to the paediatric cardiologist for further assessment. Babies with major BD discovered during these clinic visits were referred back to the geneticists to be reassessed and included in the study if a BD was confirmed.

Babies with isolated secundum atrial septal defect (ASD) or patent foramen ovale were reassessed by echocardiography at 6 to 12 months of age. Babies with a normal atrial septum were excluded from the study.

Congenital heart defects were classified into severe CHD and less severe CHD. We have adopted the European Concerted Action on Congenital Anomalies and Twins (EUROCAT) definition of "severe CHD" [10] Table 1.

Table 1 Severe congenital heart defects as utilized in the study and their ICD10 codes

\begin{tabular}{ll}
\hline Congenital heart defect & ICD10 Code \\
\hline Common arterial trunk & Q200 \\
Double outlet right ventricle & Q201 \\
Transposition of great arteries & Q203 \\
Single ventricle & Q204 \\
Atrial ventricular septal defect & Q212 \\
Tetralogy of Fallot & Q213 \\
Pulmonary valve atresia & Q220 \\
Ebstein's anomaly & Q225 \\
Aortic valve stenosis & Q230 \\
Mitral valve anomalies & Q232, Q233 \\
Hypoplastic left heart & Q234 \\
Hypoplastic right heart & Q226 \\
Aortic valve atresia and Coarctation of Aorta & Q251 \\
Aortic atresia/interrupted aortic arch & Q252 \\
Total anomalous pulmonary venous return & Q262 \\
\hline
\end{tabular}


All other types of CHD were considered less severe. Elective terminations of pregnancies for foetal anomalies were offered to the parents of foetuses with a lethal malformation complex. This procedure is according to the recently approved guidelines from the religious Scholars in the Kingdom of Saudi Arabia (Kingdom of Saudi Arabia, the general presidency of scholarly research and IFTA, 2011) [11].

Babies with isolated CHD were defined as those with CHD without any other major BD, chromosomal aberrations, and inborn errors of metabolism. The contributions of common risk factors on individual cardiac lesions were assessed only among babies with isolated CHD. The risk factors studied included maternal age $\geq$ 31 years, consanguinity (first and second cousins), insulindependent maternal diabetes mellitus, IDDM (mothers with overt diabetes mellitus and mothers with gestational diabetes on insulin), maternal body mass index (BMI) of $\geq 30$, and parity $\geq 3$. Maternal education (uneducated), maternal occupation (unemployed house wife), father occupation (solider), family income $(<7000$ Saudi Riyal (\$1866)/month, and infant sex were also included in this study.

Non-cardiac BD associated with CHD were classified into chromosomal aberration and gene mutations, specific diagnoses, genetically recognized syndromes and multiple congenital malformations (non-chromosomal and not a recognized syndrome).

Controls included a random sample of women with a normal AFAS at 18-20 weeks and newborns with no diagnosed birth defects. To select potential controls, a random sample was generated each morning by taking the list of women with a scheduled AFAS using a random number generator (http://www.random.org). If a woman was selected as a control but the foetus was found to have any BD on the AFAS, she was considered a "case".

In 2017, our paediatric cardiologist (MA) reviewed the entire cohort of babies with CHD. Echocardiography findings, cardiac catheterization results and cardiac operative findings were utilized for the final classification of CHD.

Babies were excluded from the study if:

1. Pregnant mothers were referred from other hospitals because of a foetal anomaly.

2. Newborns with major BD, including CHD, delivered elsewhere and referred to the study centre for further evaluation and management.

3. Preterm babies born at $<37$ completed weeks of gestation and exhibiting prematurity-related conditions, such as patent ductus arteriosus.

4. Newborns with isolated minor anomalies.

5. Mothers with spontaneous abortions at $<20$ weeks of gestation.
6. Newborns with mothers who had their antenatal care at PSMMC and later delivered their babies elsewhere (cases and controls).

\section{Statistical analysis}

Data were exported from the registry database to Excel spreadsheets in preparation for data analyses. Summary statistics are reported as the means \pm standard deviations for continuously measured variables and as percentages \pm standard deviations for categorical variables. Associations between categorical variables were measured by odds ratios, and a chi-squared test was used to assess the significance of these associations. Group comparisons were performed using the independent samples t-test and an analysis of variance (ANOVA). Since the sample size was large, there were no tests of normality because both the t-test and the ANOVA methodologies are robust enough in large samples against departure from normality. When the outcome of interest was measured on the binary scale (present/absent), multivariate logistic regression models were used to evaluate the effect of potential risk factors of interest on the outcome. The Type I error rate was set at 5\%. The SPSS program (IBM SPSS statistics 21.0) was used to analyse the data. A $p$-value of 0.05 was considered statistically significant.

\section{Results}

During the three-year study period, 30,351 mothers (the pregnancy cohort) gave birth to 31,032 babies (the delivery cohort), including births outside the study centre. The delivery cohort included 2107 spontaneous abortions at less than 20 weeks of gestation (6.8\%). Mothers giving birth outside the study centre (279/31,032, 0.9\%), were not included. Of 279 women, 58 women had babies with antenatally diagnosed birth defects and 221 women with unaffected pregnancies. The remaining 28,646 eligible pregnancy outcomes represent the study cohort, including 27,726 singletons and 920 newborns from multiple births (421 sets of twins and 32 sets of triplets).

Major birth defects (isolated or multiple defects within the same newborn) were diagnosed in 1179 pregnancy outcomes with a prevalence of 41.2/1000 total births (95\% CI: 38.8-43.4). CHD was diagnosed in 424 babies (36\% of babies with BD) with a prevalence of $14.8 / 1000$ total births (95\% CI: 13.4-16.2). The pattern and prevalence of various types of CHD are shown in Table 2 . Isolated secundum ASD was the most common CHD diagnosed with a prevalence of 4.7/1000 total births (95\% CI: 4.67-4.83). Isolated ventricular septal defect (VSD) was seen in 2.69/1000 total births (95\% CI: 2.1-3.3). Severe CHD was diagnosed in $7.7 \%$ of newborns with BD (91/1179) with a prevalence of 3.2/1000 total births (95\% CI: 2.55-3.85). Less severe CHD was diagnosed in 
Table 2 Prevalence and patterns of CHD types per 1000 total births (according to the EUROCAT classification) [15]

\begin{tabular}{|c|c|c|c|c|c|c|c|c|}
\hline \multirow[b]{2}{*}{ Anomaly Subgroup } & \multirow[b]{2}{*}{$\mathrm{LB}^{\dagger}(\mathrm{n})$} & \multirow[b]{2}{*}{$\mathrm{FD}^{\mathrm{a}}(\mathrm{n})$} & \multirow[b]{2}{*}{$\mathrm{LB}+\mathrm{FD}(\mathrm{n})$} & \multirow[b]{2}{*}{ LB + FD (rate) } & \multicolumn{4}{|c|}{ Excluding chromosomal aberrations } \\
\hline & & & & & $\overline{L B}(\mathrm{n})$ & $\mathrm{FD}(\mathrm{n})$ & $\mathrm{LB}+\mathrm{FD}(\mathrm{n})$ & $\overline{L B}+\mathrm{FD}$ (rate) \\
\hline CHD Total & 420 & 4 & 424 & 14.8 & 373 & 3 & 376 & 13.13 \\
\hline Severe CHD & 88 & 3 & 91 & 3.2 & 77 & 2 & 79 & 2.76 \\
\hline Common arterial truncus & 3 & 0 & 3 & 0.11 & 3 & 0 & 3 & 0.11 \\
\hline Transposition of great vessels & 13 & 0 & 13 & 0.45 & 13 & 0 & 13 & 0.45 \\
\hline Single ventricle & 6 & 0 & 6 & 0.21 & 6 & 0 & 6 & 0.21 \\
\hline Atrioventricular septal defect & 14 & 3 & 17 & 0.59 & 8 & 2 & 10 & 0.35 \\
\hline Tetralogy of Fallot & 14 & 1 & 15 & 0.52 & 13 & 1 & 14 & 0.49 \\
\hline Tricuspid atresia and stenosis & 4 & 0 & 4 & 0.14 & 4 & 0 & 4 & 0.14 \\
\hline Pulmonary valve atresia & 9 & 0 & 9 & 0.31 & 8 & 0 & 8 & 0.28 \\
\hline Aortic valve atresia/stenosis & 5 & 0 & 5 & 0.17 & 5 & 0 & 5 & 0.17 \\
\hline Hypoplastic left heart & 15 & 0 & 15 & 0.52 & 15 & 0 & 15 & 0.52 \\
\hline Hypoplastic right heart & 5 & 0 & 5 & 0.17 & 5 & 0 & 5 & 0.17 \\
\hline Coarctation of aorta & 14 & 0 & 14 & 0.49 & 11 & 0 & 11 & 0.38 \\
\hline Total anomalous pulmonary venous return & 2 & 0 & 2 & 0.1 & 2 & 0 & 2 & 0.1 \\
\hline Less severe $\mathrm{CHD}$ & 332 & 1 & 333 & 11.62 & 297 & 1 & 298 & 10.40 \\
\hline Ventricular septal defect (VSD) & 142 & 0 & 142 & 4.96 & 132 & 0 & 132 & 4.61 \\
\hline Isolated VSD & 77 & 0 & 77 & 2.69 & 72 & 0 & 72 & 2.51 \\
\hline Atrial septal defect (ASD) & 184 & 0 & 184 & 6.42 & 158 & 0 & 158 & 5.52 \\
\hline Isolated ASD & 136 & 0 & 136 & 4.75 & 115 & 0 & 115 & 4.01 \\
\hline Pulmonary valve stenosis & 21 & 1 & 22 & 0.77 & 21 & 1 & 22 & 0.77 \\
\hline
\end{tabular}

\section{${ }^{\dagger} \angle B$ live birth}

${ }^{\mathrm{a}} F D$ foetal death

333 newborns with a prevalence of 11.6/1000 total births (95\% CI: 10.38-12.86).

Table 3 shows the age at diagnosis and age at death of newborns with CHD (severe and less severe). In this analysis, we excluded mothers who did not have an

Table 3 Age at diagnosis and death of newborns with CHD

\begin{tabular}{clll}
\hline & $\begin{array}{l}\text { Total CHD } \\
(n=424)\end{array}$ & $\begin{array}{l}\text { Severe CHD } \\
(n=91)\end{array}$ & $\begin{array}{l}\text { Less severe CHD } \\
(n=333)\end{array}$ \\
\hline Age at Diagnosis & No. (\%) & No. (\%) & No. (\%) \\
Prenatal diagnosis $^{\mathrm{a}}$ & $140 / 239(58.6)$ & $54 / 63(85.7)$ & $86 / 176(48.9)$ \\
$<1$ week & $263(62.0)$ & $36(39.8)$ & $227(68.2)$ \\
$1-4$ weeks & $12(2.8)$ & $1(1.1)$ & $11(3.3)$ \\
1-12 months & $9(2.1)$ & 0 & $9(2.7)$ \\
Age at death & Deaths, N (\%) & Total cohort of CHD, \% \\
Prenatal (stillbirth) & $4(5.4)$ & 0.9 & \\
$1-30$ days & $34(45.9)$ & 8.0 & \\
1-12 months & $29(39.2)$ & 6.8 & \\
$>1$ year & $7(9.5)$ & 1.7 & \\
Total & $74(100)$ & 17.4 & \\
\hline
\end{tabular}

${ }^{a}$ The percentage was calculated as the number of foetus/baby diagnosed prenatally/total number of mothers who has antenatal foetal anomaly scan examination in each group
AFAS (185/424, 43.6\%). The overall prenatal detection rate for CHD was 33\% (140/424) and 58.6\% (140/239) among mothers with an AFAS. The prenatal detection rate for pregnancies with an AFAS was 85.7\% (54/63) for severe $\mathrm{CHD}$ ), and the prenatal detection rate for pregnancies with an AFAS was $48.9 \%$ (86/176) for less severe CHD. Twenty-eight mothers (30.8\%) who carried foetuses with severe CHD did not have an AFAS. All newborns with severe CHD detected postnatally (except one) were diagnosed within the first week after birth.

None of the pregnancies with a prenatal diagnosis of CHD were electively terminated. There were 74 (17.4\% of total CHD) foetuses or newborns who died during the follow-up period, with almost all the deaths occurring in the first year of life (Table 3).

The Kaplan-Meier survival curve for babies with $\mathrm{CHD}$, other BD, and controls (Fig. 1) shows that the $50 \%$ cumulative survival for babies with severe CHD was approximately 250 days compared with a survival of 1000 days for babies with all other birth defects. $(p=<0.00001)$.

As shown in Fig. 2, isolated CHD defects were seen in $59.9 \%(254 / 424)$ of the group, and associated extra-cardiac congenital malformations were found in $40.1 \%$ (170/424) of the CHD group. There were 51 of 424 


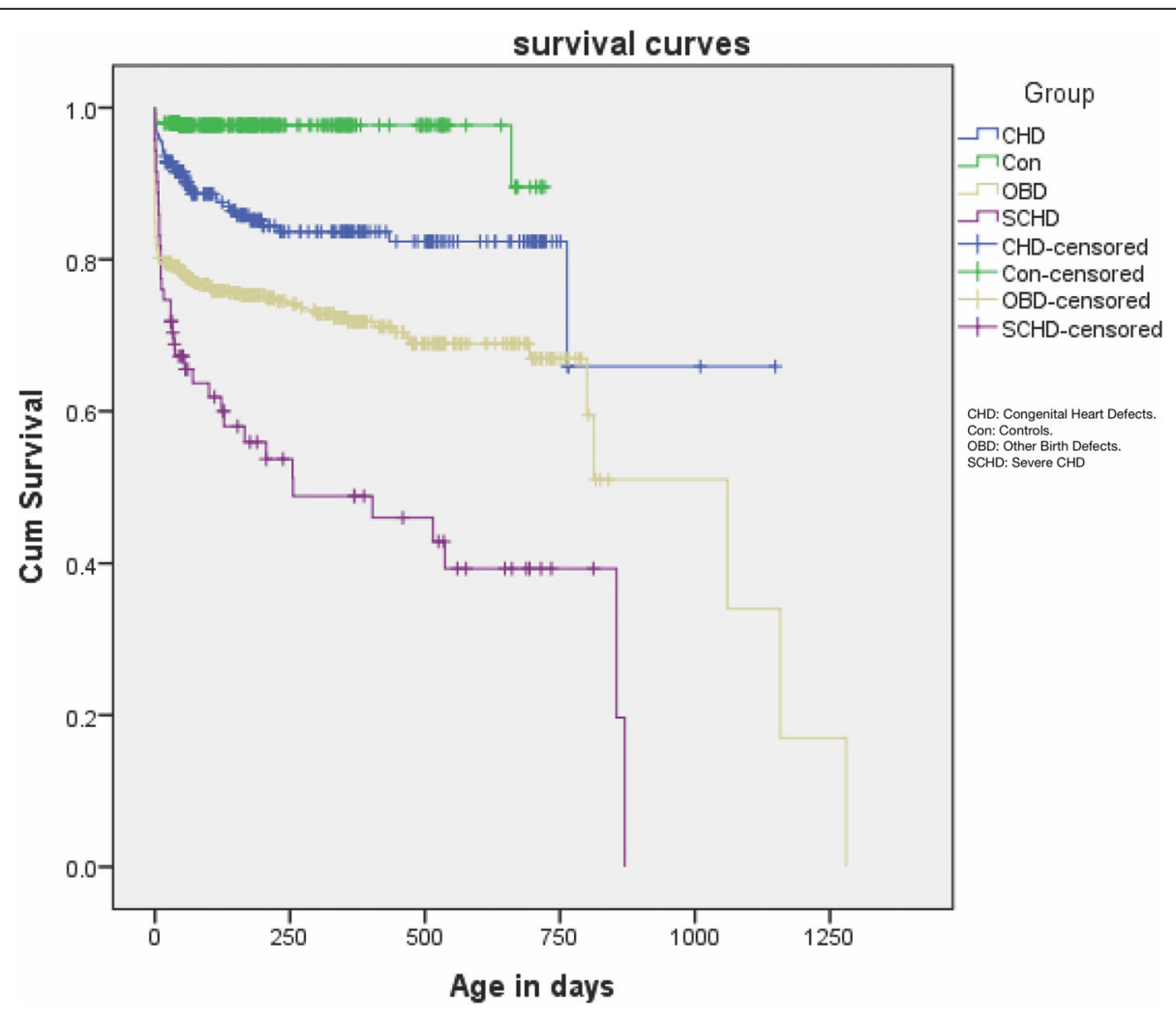

Footnotes:

Overall Comparisons

\begin{tabular}{|l|c|c|c|}
\hline & Chi-Square & $\mathrm{df}$ & Sig. \\
\hline Log Rank (Mantel-Cox) & 136.159 & 3 & .000 \\
\hline
\end{tabular}

Fig. 1 Kaplan Meier survival curve. Test of equality of survival distributions for the different levels of Group. Censored observation means the patient does not experience the event of interest (death), in our study, during the follow up period

(12\%) babies with chromosomal aberrations, including $37(72.5 \%)$ babies with trisomy 21 . Specific diagnoses were made in $66(66 / 424,16 \%)$ babies and included renal malformations in $14(14 / 66,21.2 \%)$ babies, diaphragmatic hernia in $8(12.1 \%)$ babies and orofacial cleft in $7(10.6 \%)$ babies. Recognizable specific syndromes were found in $12(12 / 424,2.8 \%)$ babies and included Ellis Van Creveld in 3 (3/12, 25\%) babies, Dandy-Walker syndrome in $2(16.7 \%)$ babies, and others rare syndromes in 7 (58.3\%) babies. Thirty-nine (39/424, 9.2\%) of the newborns had non-chromosomal and non-syndromic multiple congenital malformations. Drug embryopathy (sodium valproate and topiramate) was found in 2 of 424 newborns $(0.5 \%)$.

There were no differences in sex among the total CHD group. In the severe CHD group, there was a significant male predominance $(50 / 91$ or $54.9 \%)$ with an OR of 1.7 (95\% CI: 1.13-2.66, $p=0.01$ ).
Parental sociodemographic characteristics as risk factors for babies with CHD were analysed for all CHD, severe $\mathrm{CHD}$, and $\mathrm{CHD}$ without associated anomalies or syndromes (I-CHD) and controls and are shown in Table 4. In our sample, 254 (254/424, 59.9\%) babies had isolated CHD. Maternal age $\geq 31$ years, maternal BMI $\geq 30$, and uneducated mothers were statistically significant risk factors for the entire cohort of CHD, I-CHD, and severe $\mathrm{CHD}$ groups. Consanguinity, as a risk factor for the entire cohort of $\mathrm{CHD}$, was statistically significant with an OR of 1.30 (95\% CI: $1.04-1.62, p=0.02$ ) but not for the I-CHD group (OR 1.41, 95\% CI: 0.922.16, $p=0.13)$.

Multivariate logistic regression analysis was applied for the total cohort of CHD, I-CHD, and severe CHD groups separately (Table 5 ). Maternal age $\geq 31$ years, maternal $\mathrm{BMI} \geq 30$, insulin-dependent maternal diabetes (IDDM), and maternal occupation as an unemployed 


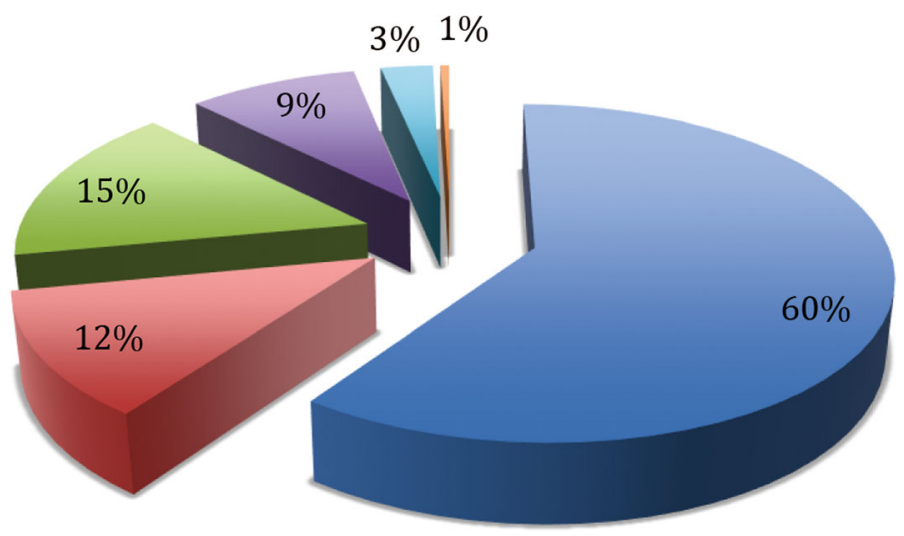

\section{Isolated CDH}

- Sepecific Diagnoses

- Recognized syndroms
- Chromosomal changes

- Multiple Dysmorphic Features

- Drug embryopathy

Fig. 2 Congenital heart defects with extra-cardiac birth defects

housewife were significant risk factors for CHD in all three CHD groups. Maternal IDDM was found in 10.6\% (45/424) of mothers of babies with CHD compared with $3.0 \%$ of controls mothers (OR 3.8, 95\% CI: $2.44-5.79$, $p=<0.00001$.

Multivariate logistic regression analysis for individual cardiac lesions (among the I-CHD group only) was applied for 5 risk factors as follows: maternal age $\geq 31$ years, consanguinity, maternal IDDM, maternal BMI $\geq 30$, and sex. Ventricular septal defect (VSD) was associated with maternal age $\geq 31$ years (OR 1.58, 95\% CI: 1.06-2.36, $p=0.02$ ) and maternal IDDM (OR 1.75, 95\% CI: $0.99-0.3 .09, p=0.05)$. Secundum ASD was associated with maternal IDDM (OR 2.66, 95\% CI: 1.65-4.28, $p=<0.0001$ ) and $\mathrm{BMI} \geq 30$ (OR 1.66, 95\% CI: 1.12-2.47, $p=0.04$ ). All other major types of CHD were not associated with these risk factors.

\section{Discussion}

In our study, foetuses and/or babies with CHD were determined by an AFAS and postnatal examination over a 3-year period from a study cohort of 28,646 eligible births. The total CHD prevalence was 14.8/1000 total births, which was higher than previously reported from Saudi Arabia (2.1-10.7/1000 live births) [3, 12], Middle Eastern countries (7.1-8.6/1000 live births) [13, 14], and Western countries $(7.64-11.5 / 1000$ births) $[15,16]$. The severe CHD prevalence of 3.2/1000 total births (95\% CI: 2.55-3.85) was also higher than that reported by the EUROCAT Network at 2.34/1000 live births (95\% CI:
2.28-2.39, $p=0.00006$ ) [15]. We found a high prevalence of ASD secundum and VSD, which was similar to another study from Saudi Arabia [17].

These differences between prevalences could be due to different study methodologies, including longitudinal vs. cross-sectional, and retrospective analysis of charts vs. prospective studies. Additionally, inclusion of trivial lesions, stillbirths, and elective terminations of pregnancies for foetal anomalies could influence the prevalence. In addition, ethnic, genetic and/or environmental risk factors, such as maternal age, maternal illness, BMI and others, influence CHD prevalence [18, 19]. Although the contributions and the mode of actions of risk factors are debated, there is increasing evidence from epidemiological studies that indicate temporal relationships between these risk factors and CHD [18, 19]. In our study, maternal age $\geq 31$ years, body mass index of $\geq 30$, parity of $\geq 3$, uneducated mothers, unemployed housewives, insulin-dependent maternal diabetes mellitus, and consanguinity were significantly higher among mothers of affected babies than controls and may have contributed to the high prevalence of CHD in our population.

The CHD prenatal detection rate of $58.2 \%$ among mothers who had an AFAS (140/239) was slightly lower than the $68.3 \%$ prenatal detection rate recently reported [20]. The low detection rate for the less severe CHD group in our study could be due to the high number of cases of isolated secundum ASDs (136/333, 40.8\%) and isolated VSDs $(77 / 333,23.1 \%)$, which may be missed on an AFAS. In addition, almost half of the pregnant 
Table 4 Parental sociodemographic characteristics of newborns/babies with CHD and controls

\begin{tabular}{|c|c|c|c|c|c|}
\hline \multirow[t]{2}{*}{ CHD groups (Total number) } & \multicolumn{5}{|c|}{ Maternal age $\geq 31$ years } \\
\hline & Cases No. (\%) & ${ }^{a}$ Controls No. (\%) & OR & $95 \% \mathrm{Cl}$ & $p$ value \\
\hline Total CHD $(T C H D=424)$ & $229(54.0)$ & $520(41.2)$ & 1.67 & $1.34-2.09$ & $<0.0005$ \\
\hline Severe CHD $(\mathrm{SCHD}=91)$ & $50(54.9)$ & & $1 \cdot 70$ & $1.13-2.66$ & 0.01 \\
\hline \multirow[t]{3}{*}{ Isolated CHD (ICHD = 254) } & $136(53.5)$ & & 1.64 & $1.25-2.15$ & 0.0003 \\
\hline & \multicolumn{5}{|c|}{ Body Mass Index $\geq 30$} \\
\hline & Cases & Controls & & & \\
\hline $\mathrm{TCHD}$ & $186(43.9)$ & $453(35.9)$ & 1.42 & $1.13-1.77$ & 0.002 \\
\hline $\mathrm{SCHD}$ & $43(47.3)$ & & 1.6 & $1.04-2.45$ & 0.03 \\
\hline \multirow[t]{3}{*}{$\mathrm{ICHD}$} & $118(46.5)$ & & 1.54 & $1.18-2.03$ & 0.001 \\
\hline & \multicolumn{5}{|c|}{ Insulin-dependent maternal diabetes mellitus - IDDM ${ }^{b}$} \\
\hline & Cases & Controls & & & \\
\hline $\mathrm{TCHD}$ & $45(10.6)$ & $38(3.0)$ & 3.82 & $2.44-5.98$ & $<0.0001$ \\
\hline $\mathrm{SCHD}$ & $8(8.8)$ & & 2.10 & $1.40-6.87$ & 0.008 \\
\hline \multirow[t]{3}{*}{ ICHD } & $20(7.9)$ & & 2.75 & $1.57-4.80$ & 0.0004 \\
\hline & \multicolumn{5}{|l|}{ Consanguinity } \\
\hline & Cases & Controls & & & \\
\hline $\mathrm{TCHD}$ & $220(50.9)$ & $571(45.2)$ & 1.30 & 1.041 .62 & 0.02 \\
\hline $\mathrm{SCHD}$ & $49(53.8)$ & & 1.41 & $0.92-2.16$ & 0.13 \\
\hline \multirow[t]{3}{*}{ ICHD } & $126(49.6)$ & & 1.19 & $0.90-1.56$ & 0.22 \\
\hline & \multicolumn{5}{|c|}{ Improper Folic Acid Intake ${ }^{c}$} \\
\hline & Cases & Controls & & & \\
\hline $\mathrm{TCHD}$ & $378(89.2)$ & $1134(89.9)$ & 0.92 & $1.04-1.62$ & 0.71 \\
\hline $\mathrm{SCHD}$ & 79 (86.8) & & 0.74 & $0.38-1.40$ & 0.45 \\
\hline \multirow[t]{3}{*}{ ICHD } & $229(90.2)$ & & 1.03 & $0.65-1.62$ & 0.94 \\
\hline & \multicolumn{5}{|l|}{ Sex (male) } \\
\hline & Cases & Controls & & & \\
\hline $\mathrm{TCHD}$ & $210(49.5)$ & 645 (16.7) & 0.94 & $0.75-1.16$ & 0.61 \\
\hline $\mathrm{SCHD}$ & $50(54.9)$ & & 1.16 & $0.76-1.78$ & 0.54 \\
\hline \multirow[t]{3}{*}{ ICHD } & $128(50.4)$ & & 0.97 & $0.74-1.27$ & 0.89 \\
\hline & \multicolumn{5}{|l|}{ Parity $\geq 3$} \\
\hline & Cases & Controls & & & \\
\hline $\mathrm{TCHD}$ & $221(52.1)$ & $553(43.8)$ & 1.39 & $1.12-1.74$ & 0.003 \\
\hline $\mathrm{SCHD}$ & $47(51.6)$ & & 1.37 & $0.89-2.09$ & 0.18 \\
\hline \multirow[t]{3}{*}{$\mathrm{ICHD}$} & 131 (51.6) & & 1.36 & $1.04-1.79$ & 0.02 \\
\hline & \multicolumn{5}{|c|}{ Mother occupation (unemployed house wife) } \\
\hline & Cases & Controls & & & \\
\hline $\mathrm{TCHD}$ & $317(74.8)$ & $1007(79.8)$ & 0.75 & $0.57-0.97$ & 0.03 \\
\hline $\mathrm{SCHD}$ & $74(81.3)$ & & 1.10 & $0.63-1.90$ & 0.82 \\
\hline \multirow[t]{3}{*}{ ICHD } & 187 (73.6) & & 0.70 & $0.51-0.96$ & 0.03 \\
\hline & \multicolumn{5}{|c|}{ Mother education (uneducated) } \\
\hline & Cases & Controls & & & \\
\hline $\mathrm{TCHD}$ & $144(34.0)$ & $333(26.38)$ & 1.43 & $1.13-1.81$ & 0.003 \\
\hline $\mathrm{SCHD}$ & $37(40.7)$ & & 1.91 & $1.23-2.96$ & 0.004 \\
\hline $\mathrm{ICHD}$ & $85(33.1)$ & & 1.40 & $1.04-1.87$ & 0.02 \\
\hline
\end{tabular}


Table 4 Parental sociodemographic characteristics of newborns/babies with CHD and controls (Continued)

\begin{tabular}{|c|c|c|c|c|c|}
\hline & \multicolumn{5}{|c|}{ Father occupation (soldier) } \\
\hline & Cases & Controls & & & \\
\hline $\mathrm{TCHD}$ & $285(67.2)$ & $896(80.0)$ & 0.83 & $0.66-1.06$ & 0.15 \\
\hline $\mathrm{SCHD}$ & $68(74.7)$ & & 1.20 & $0.74-1.96$ & 0.50 \\
\hline \multirow[t]{3}{*}{$\mathrm{ICHD}$} & $170(66.9)$ & & 0.83 & $0.62-1.10$ & 0.22 \\
\hline & \multicolumn{5}{|c|}{ Income Saudi Riyal $\leq 7000$ (\$1866) /month } \\
\hline & Cases & Controls & & & \\
\hline $\mathrm{TCHD}$ & $170(40.1)$ & $488(36.7)$ & 1.06 & $0.84-1.32$ & 0.64 \\
\hline $\mathrm{SCHD}$ & $38(41.8)$ & & 1.13 & $0.73-1.74$ & 0.63 \\
\hline $\mathrm{ICHD}$ & $101(39.8)$ & & 1.04 & $0.79-1.38$ & 0.79 \\
\hline
\end{tabular}

${ }^{a}$ Controls (1262) are utilized for comparison with each of the CHD groups separately

bIDDM, included overt DM and gestational DM required insulin

Improper folic acid intake, included folic acid used postconceptionally, irregular use or not been used during current pregnancy

women who carried foetuses with I-CHD in our study (47.1\%, 157/333) did not have an AFAS. Our prenatal detection rate of $85.7 \%(54 / 63)$ among foetuses with severe CHD is comparable to a recent report from the Netherlands with a prenatal detection rate of more than $93 \%$ among foetuses with critical heart lesions [21]. The issue of prenatal detection for severe CHD needs to be addressed by more thorough training of ultrasonographers in antenatal ultrasound screening techniques. Improvement in prenatal diagnosis has been shown to improve the timing, mode of delivery, and immediate postnatal management of babies with CHD [22].

Associated extra-cardiac malformations with CHD occurred in $40 \%$ of babies in our study compared to 26 and 23\% from those in reports from Europe [23, 24] and India [25].

Chromosomal aberrations were the most commonly associated anomalies $(51 / 170,30.0 \%)$ with trisomy 21 (Down syndrome) representing 73\% (37/51) of the cases. The high proportion with trisomy 21 could be explained by the high maternal age (mean age $31.6 \pm 6.5$, range $17-47$ years) and no first trimester screening for Down syndrome in Saudi Arabia. Elective termination of pregnancy for foetal anomalies for trisomy 21 is not allowed in Saudi Arabia (unless associated with severe BDs) because of religious convictions.

We previously reported a consanguinity prevalence rate of $55 \%$ in this population [26]. In our current analysis, consanguinity was a significant risk factor for the entire cohort of infants with CHD (OR 1.3, 95\% CI: 1.04-1.81, $p=0.02$ ) but was not significant risk factor for the group with CHD and no associated other anomalies (OR 1.41, 95\% CI: 0.92-2.16, $p=0.13$ ). This result may indicate that consanguinity as a risk factor is mediated through various inherited conditions and cases with multiple birth defects, rather than a direct effect on
CHD. Consanguinity as a risk factor for CHD and for individual cardiac lesions has been widely debated [27-29]. In our study, the effect of consanguinity (first- and second-cousin marriage) on individual cardiac lesions (among the group of CHD without associated anomalies) was evaluated using multivariate logistic regression analysis. Consanguinity was not statistically significant for any specific cardiac defect. Other studies have reported a statistically significant association of consanguinity for specific congenital cardiac lesions [26-28]. Maternal insulin-dependent diabetes was a risk factor for secundum ASD and VSD only (OR 2.66, 95\% CI: $1.65-4.28, p=<0.0001$ and OR 1.75, 95\% CI: $0.99-3.09, p=0.05$, respectively). These results agree with those of Garne et al. using EUROCAT data [30].

The alarmingly high prevalence of maternal insulindependent diabetes of 10.6 and 3\% among mothers of cases and controls (Table 4) is almost similar to $11.6 \%$ among Saudi females at 30-39 years reported by Al-Nozha et al. [31]. In our study, maternal age was only a significant risk factor for VSD (OR 1.58, 95\% CI: 1.06$2.36, p=0.02$ ). For other lesions, the analysis was limited due to low numbers.

The strengths of our study included the involvement of paediatric cardiologists for both prenatally and postnatally suspected cases of CHD, the inclusion of stillbirth with CHD, and the relatively long followup period ( $2-5$ years).

Although the Saudi army recruits from all sectors of the Saudi society, the inclusion of only Saudi army personnel may represent a study limitation. There was a high proportion of uneducated mothers with high parity (higher than 3). Additionally, we excluded infants from mothers who delivered elsewhere (cases and controls) as we were not able to verify their AFAS findings and confirm postnatal diagnosis, which is another limitation of the study. 
Table 5 Multivariate logistic regression analysis for risk factors for CHD

\begin{tabular}{|c|c|c|c|}
\hline Variable & OR & $95 \% \mathrm{Cl}$ & $p$ Value \\
\hline \multicolumn{4}{|l|}{ Total CHD (424) } \\
\hline Mother age $\geq 31$ years & 1.51 & $1.15-1.98$ & 0.002 \\
\hline $\mathrm{BMI}^{\mathrm{a}} \geq 30$ & 1.21 & $0.96-1.51$ & 0.09 \\
\hline $\mathrm{IDDM}^{\mathrm{b}}$ & 2.54 & $1.69-3.75$ & $<.0001$ \\
\hline Sex (male) & 1.32 & $1.07-1.63$ & 0.009 \\
\hline Parity $\geq 3$ & 0.90 & $0.68-1.18$ & 0.45 \\
\hline Income < 7000 Saudi Riyal (\$1866) & 1.10 & $0.85-1.43$ & 0.45 \\
\hline $\begin{array}{l}\text { Mother occupation (Unemployed } \\
\text { house wife) }\end{array}$ & 0.77 & $0.60-0.99$ & 0.04 \\
\hline Mother education (Uneducated) & 1.31 & $1.03-1.67$ & 0.02 \\
\hline \multicolumn{4}{|l|}{ Isolated CHD (254) } \\
\hline Mother age $\geq 31$ years & 1.413 & $1.01-1.97$ & 0.04 \\
\hline $\mathrm{BMI} \geq 30$ & 1.37 & $1.03-1.79$ & 0.02 \\
\hline IDDM & 1.43 & $0.85-2.39$ & 0.13 \\
\hline Sex (male) & 1.27 & $0.97-1.65$ & 0.07 \\
\hline Parity $\geq 3$ & 0.87 & $0.62-1.25$ & 0.41 \\
\hline Income < 7000 Saudi riyal (\$1866) & 0.97 & $0.71-1.36$ & 0.93 \\
\hline $\begin{array}{l}\text { Mother occupation (Unemployed } \\
\text { house Wife) }\end{array}$ & 0.73 & $0.54-0.99$ & 0.04 \\
\hline Mother education (Uneducated) & 1.3 & $0.96-1.74$ & 0.08 \\
\hline \multicolumn{4}{|l|}{ Severe CHD (91) } \\
\hline Mother age $\geq 31$ years & 1.71 & $1.00-2.94$ & 0.04 \\
\hline $\mathrm{BMI} \geq 30$ & 1.36 & $0.87-2.11$ & 0.16 \\
\hline IDDM & 1.44 & $0.66-3.28$ & 0.35 \\
\hline Sex (male) & 0.98 & $0.65-1.52$ & 0.94 \\
\hline Parity $\geq 3$ & 0.78 & $0.46-1.35$ & 0.38 \\
\hline Income < 7000 Saudi Riyal (\$1866) & 0.96 & $0.75-1.23$ & 0.10 \\
\hline $\begin{array}{l}\text { Mother occupation (Unemployed } \\
\text { house Wife) }\end{array}$ & 1.03 & $0.58-1.83$ & 0.89 \\
\hline Mother education (Uneducated) & 1.58 & $1.00-2.49$ & 0.04 \\
\hline
\end{tabular}

${ }^{\mathrm{a} B M I}$ maternal body mass index

${ }^{\mathrm{b}}$ IDDM insulin-dependent maternal diabetes (Overt and gestational)

\section{Conclusions}

In this Saudi population, we report a high prevalence of CHD compared with other Middle East and Western countries. As prenatal diagnosis of CHD may improve outcomes, there is a need for a higher uptake of an AFAS in this population. We found several modifiable CHD risk factors that underscore the importance of public health programmes aimed at tackling and preventing such risk determinants for $\mathrm{CHD}$, which could reduce the prevalence of CHD.

\section{Abbreviations}

AFAS: Antenatal Foetal Anomaly Scan; ASD: Atrial Septal Defect; BD: Birth Defects; BMI: Body Mass Index; CHD: Congenital Heart Defects; EUROCAT: European Concerted Action on Congenital Anomalies and Twins; I-CHD: Isolated CHD;
IDDM: Insulin Dependent Diabetes Mellitus; PSMMC: Prince Sultan Military Medical City; S-CHD: Severe CHD; T-CHD: Total CHD; VSD: Ventricular Septal Defect

\begin{abstract}
Acknowledgements
We would like to thank King Abdul-Aziz city for science and technology \& NSTIP for their support to this study. We would like to thank the Medical Services Directorate of the Saudi Armed Forces and the Prince Sultan Military Medical City directorate for their unlimited support during the initiation and execution of the study. Our unlimited thanks and appreciation also goes to our advisory board (Professors; Castilla E., Mastroiacovo P., Botto L., Alkuraya F., and Dr. Kurdi W.) during the preparation/discussion of the study proposal and execution of the study. We would like to thank our secretaries for their commitment and enthusiasm.
\end{abstract}

\section{Funding}

This project was supported by a grant from King Abdul-Aziz city for science and technology through the national science, technology and innovation plan. Project No: 09-MED748-21.

\section{Availability of data and materials}

The data that support the findings of this study are available from [King AbdulAziz City for Science and Technology]. Data are however available from the authors upon reasonable request and with permission of [King AbdulAziz City for Science and Technology].

\section{Consent of participant}

Parental request was obtained for cord blood collections from babies with BD for future DNA study.

\section{Authors' contributions}

MAMS, study conception and design, drafting and revising the manuscript. $M A$, reviewed all the CHD cases, revised the manuscript. ANA, study design, data collection, revised the manuscript. $\mathrm{AMH}$, data collection, revised the manuscript. MSR, study design, data collection. MS, statistical analysis and revised the manuscript. $E G$, study conception and design, revised the manuscript. AMK, study conception and design, revised the manuscript. All authors approved the submission of the manuscript.

Ethics approval and consent to participate

The study approved by the research and ethical Committee of PSMMC (Project No. 366, series of 2009).

\section{Consent for publication}

Not applicable

\section{Competing interests}

The authors declare that they have no competing interests.

\section{Publisher's Note}

Springer Nature remains neutral with regard to jurisdictional claims in published maps and institutional affiliations.

\section{Author details}

${ }^{1}$ Division of neonatal medicine, department of Paediatrics, Prince Sultan Military Medical City, W932, P. O. Box 7897, Riyadh 11159, Kingdom of Saudi Arabia. ${ }^{2}$ Paediatric cardiology department, Prince Sultan cardiac center, Riyadh 11159, Kingdom of Saudi Arabia. ${ }^{3}$ Division of medical genetic, department of Paediatrics, Prince Sultan Military Medical City, Riyadh 11159, Kingdom of Saudi Arabia. ${ }^{4}$ Division of foetal medicine, department of Obstetrics and Gynaecology, Prince Sultan Military Medical City, Riyadh 11159, Kingdom of Saudi Arabia. ${ }^{5}$ Department of epidemiology and biostatistics, Schulich School of medicine and dentistry, University of western Ontario, London, Ontario, Canada. ${ }^{6}$ Department of Paediatrics, Hospital Lillebaelt-Kolding, 6000 Kolding, Denmark. 
Received: 8 October 2018 Accepted: 6 March 2019

Published online: 20 March 2019

\section{References}

1. Azhar AS, AIShammasi ZH, Higgi RE. The impact of congenital heart diseases on the quality of life of patients and their families in Saudi Arabia. Biological, psychological, and social dimensions. Saudi Med J. 2016;37(4):392-402.

2. Hoffman JIE, Kaplan S. The incidence of congenital heart disease. J Am Coll Cardiol. 2002;39(12):1890-900

3. Alenezi AM, Albawardi NM, Ali A, Househ MS, Elmetawally A. The epidemiology of congenital heart diseases in Saudi Arabia: a systematic review. J Public Health Epidemiol. 2015;7(7):232-40.

4. Van der Linde D, Konings EEM, Slager MA, et al. Birth prevalence of congenital heart disease worldwide: a systemic review and meta-analysis. J Am Coll Cardiol. 2011:58:2241-7.

5. Abbag F. Pattern of congenital heart disease in the southwestern region of Saudi Arabia. Ann Saudi med. 1998;18(5):393-5.

6. Sandridge AL. Risk Factors for Congenital Heart Defects in Saudi Arabian Babies. PhD thesis, London School of Hygiene \& Tropical Medicine 2007.

7. Al-Mesned A, Al Akhfash AA, Sayed M. Incidence of severe congenital heart disease at the province of Al-Qassim. Saudi Arabia Congenit Heat Dis. 2012; 7(3):277-82.

8. Bonnet D, Coltri A, Butera G, et al. Prenatal diagnosis of transposition of great vessels reduces neonatal morbidity and mortality. Arch Mal Coeur Vaiss. 1999;92(5):637-40.

9. de-Wahl Granelli A, Wennergren M, Sandberg K, et al. Impact of pulse oximetry screening on the detection of duct dependent congenital heart disease: a Swedish prospective screening study in 39821 newborns. BMJ. 2009;338:a3037.

10. EUROCAT. Eurocat guide 1.3 Instructions for registration and surveillance of congenital anomalies. 2005. Available at: http:// www.eurocat-network.eu/ aboutus/datacollection/edmp.

11. Kingdom of Saudi Arabia. The general presidency of scholarly research and Ifita, resolution of the commission of senior scholars in Saudi Arabia. 2011; No. 240. dated 06/02/1432 Hijjra year (10/01/2011). http://www.alifta.net.

12. Fida NM, Al-Aama J, Nichols W, Alqahtani M. A prospective study of congenital malformations among live born neonates at a university hospital in western Saudi Arabia. Saudi Med J. 2007;28(9):1367-73.

13. Nikyar B, Sedehi M, Mirfazeli A, Qorbani M, Golalipour MJ. Prevalence and pattern of congenital heart disease among neonates in Gorgan, northern Iran (2007-2008). Iran J Pediatr. 2011;21(3):307-12.

14. Subramanyan R, Joy J, Venugopalan JP, Sapru A, al Khusaiby SM. Incidence and spectrum of congenital heart disease in Oman. Ann Trop Paediatr. 2000;20(4):337-41.

15. EUROCAT. Cases and prevalence (per 10,000 births) for all full member registries from 2011 to 2015. 2015. Available at: http://www.eurocatnetwork.eu/accessprevalencedata/prevalencetables.

16. Ferencz C, Rubin JD, McCarter RJ, et al. Congenital heart disease: prevalence at livebirth. The Baltimore-Washington infant study. Am J Epidemiol. 1985; 121(1):31-6.

17. Alabdulgader AAA. Congenital heart disease in Saudi Arabia: current epidemiology and future projections. East Mediterr Health J. 2006: 12(Suppl 2):S157-67.

18. Tikkanen J, Heinonen OP. Risk factors for cardiovascular malformations in Finland. Eur J Epidemiol. 1990;6:348-6.

19. Jenkins KJ, Correa A, Feinstein JA, et al. Noninherited risk factors and congenita cardiovascular defects: current knowledge a scientific statement from the american heart association council on cardiovascular disease in the young. Circulation. 2007;115:2995-3014

20. Landis BJ, Levey A, Levasseur SM, et al. Prenatal diagnosis of congenital heart disease and birth outcomes. Pediatr Cardiol. 2013;34(3):597-5.

21. van Velzen CL, Clur SA, Rijlaarsdam MEB, et al. Prenatal detection of congenital heart disease-results of a national screening programme. BJOG. 2016;123: 400-7.

22. Trento LU, Pruetz JD, Chang RK, Detterich J, Sklansky MS. Prenatal diagnosis of congenital heart disease: impact of mode of delivery on neonatal outcome. Prenat Diagn. 2012;32(13):1250-5.

23. Eskedal L, Hagemo P, Eskild A, Aamodt G, Seiler KS, Thaulow E. A populationbased study of extra-cardiac anomalies in children with congenital cardiac malformations. Cardiol Young. 2004;14(6):600-7.
24. Stoll C, Dott B, Alembik Y, Roth MP. Associated noncardiac congenital anomalies among cases with congenital heart defects. Eur J Med genet. 2015;58(2):75-85.

25. Sawant SP, Amin AS, Bhat M. Prevalence, pattern and outcome of congenital heart disease in Bhabha Atomic Research Centre Hospital, Mumbai. Indian J Pediatr. 2013;80(4):286-91.

26. Majeed-Saidan MA, Ammari AN, AlHashem AM, et al. Effect of consanguinity on birth defects in Saudi women: results from a nested case-control study. Birth Defects Res (Part A), Clin Mol Teratol. 2015;103(2):100-4.

27. Becker S, Al HZ. First-cousin mating's and congenital heart disease in Saudi Arabia. Community Genet. 1999;2(2-3):69-73.

28. Becker SM, Al Halees Z, Molina C, Paterson RM. Consanguinity and congenital heart disease in Saudi Arabia. Am J Med Genet. 2001;99:8-13.

29. Shieh JT, Bittles AH, Hudgins L. Consanguinity and the Risk of Congenital Heart Disease. Am J Med Genet A. 2012;158 A(5):1236-41.

30. Garne $E$, Loane $M$, Dolk H, et al. Spectrum of congenital anomalies in pregnancies with Pregestational diabetes. Birth Defects Res (Part A). 2012;94:134-40.

31. Al-Nozha MM, Al-Maatouq MA, Yaqoub Y, et al. Diabetes mellitus in Saudi Arabia. Saudi Med J. 2004;25(11):1603-10
Ready to submit your research? Choose BMC and benefit from:

- fast, convenient online submission

- thorough peer review by experienced researchers in your field

- rapid publication on acceptance

- support for research data, including large and complex data types

- gold Open Access which fosters wider collaboration and increased citations

- maximum visibility for your research: over $100 \mathrm{M}$ website views per year

At $\mathrm{BMC}$, research is always in progress.

Learn more biomedcentral.com/submissions 